\title{
Occupational accidents presenting to the accident and emergency department
}

\author{
C. HARKER, ${ }^{*}$ A. B. MATHESON, J. A. S. ROSS \& \\ A. SEATON \\ Department of Environmental \& Occupational Medicine, University of Aberdeen \\ Medical School, Foresterhill, and *Accident and Emergency Department, Aberdeen Royal \\ Infirmary, Foresterhill, Aberdeen.
}

\section{SUMMARY}

A prospective survey of patients attending the major Accident and Emergency Department in Aberdeen was undertaken. This department serves a population of 500000 and sees some $50 \%$ of all accidents in the region. All work-related injuries were identified and information relating to the circumstances of the accident, injury sustained, and treatment required was sought. Work-related injuries accounted for $16.5 \%$ of new patients attending the department. The commonest injury type was a laceration to a finger. Three hundred and eighty diagnostic $X$-rays were undertaken and a total of 910 treatments were required over a 27-day period. On an annual basis, it is estimated that some 5100 radiographs and 12300 medical treatments would be required for work-related accidents. It is estimated that $30 \%$ of injuries to the hands and feet would have been prevented by the wearing of appropriate personal protective equipment. The majority of workplace accidents were correctly referred to $A \& E$ and any efforts to reduce this workload must concentrate on preventive measures in the workplace.

This paper suggests that documenting work-related accidents and determining targets for preventive action would reduce the number of attendances at A\&E units with a potential significant saving for industry and the National Health Service.

\section{INTRODUCTION}

In the U.K. there is a statutory obligation for employers to notify certain workplace injuries or dangerous occurrences to the Health and Safety Executive or local

Correspondence: $\operatorname{Dr}$ C. Harker, Department of Environmental \& Occupational Medicine, University Medical School Foresterhill, Aberdeen AB9 2ZD. 
authority. Under the Reporting of Injuries, Diseases and Dangerous Occurrences Regulations, 1985 (RIDDOR) (Health and Safety Commission, 1986) reportable injuries include all work-related injuries causing absence for 3 days or more, specific major injuries including fractures, amputations, loss of sight or those?

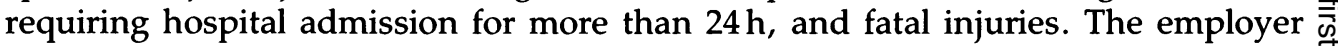
must be made aware of the nature of the injury by the employee's doctor for 0 the system to work. Substantial under-reporting is thought to exist and a review of the RIDDOR reporting system is taking place in 1991 (Health and Safety Commission, 1990). In a previous report risk of work related accidents in different industrial sectors was estimated and the high rates of specific injuries in particular industries, namely lacerations from knives in food and fish processing and eye injuries in mechanical engineering were described (Harker et al., 1991). We describe below the workload that these and other occupational accidents produce for the A\&E Department in Aberdeen.

In the year during which this study took place the A\&E Department in Aberdeen treated $51.3 \%$ of all new casualty patients and $53.3 \%$ of the total attendances to A\&E units in Grampian (Grampian Health Board, 1990). An eye casualty unit on the same site was open from 9.00 a.m. to 5.00 p.m. during working days. S Approximately $40 \%$ of the 500000 population of Grampian live in the city of $\vec{c}$ Aberdeen which is a major centre for the oil industry and has large service, paper $\frac{\complement}{\bar{D}}$ making, food manufacturing and engineering sectors.

The aims of the study were to define the workload of the A\&E Department as a result of people attending with work-related injuries, and to suggest a working scheme for accident and occupational health units whereby preventive action could be directed at a local level.

\section{PATIENTS AND METHODS}

We studied all patients attending the A\&E Department of Aberdeen Royal Infirmary from 16 January 1989 to 11 February 1989 inclusive. We did not include those patients attending a separate eye casualty department during working hours on weekdays. All patients were asked by a clerk if their accident occurred at work, travelling in the course of work or working at home. All those who answered positively were entered into the study and completed a questionnaire. Information was sought on occupation and employer, and on location, date and time of the accident. In addition, the nature of the job, the circumstances of the accident and the type of injury were recorded. The casualty records of patients entering the $N$ study were stamped with an identifying mark and retrieved after the course of $N$ treatment had been completed, when further details of the injury and its manage- N ment were recorded. Checks were undertaken to ensure all accident cases had been included.

The occupations of individuals were coded to group and unit level according to the classification of the Office of Population Censuses and Surveys, while industry was classified by the Standard Industrial Classification 1980 (Central Statistical Office, 1980). External causes of accidents were coded as in Section $E$ of the 
International Classification of Diseases, Volume 8, as adopted by the Health and Safety Executive form 2508 (Health and Safety Executive, 1986). Injuries were coded by nature and site.

\section{RESULTS}

During the study period exactly 3500 patients attended the A\&E Department, of whom $578(16.5 \%)$ admitted to a work-related accident. Of these $472(82 \%)$ were male. Over half $(54 \%)$ were between the the ages of 15 and 30 and no males over the age of 65 reported a work related accident. This broadly reflects the age structure of the workforce. The proportion of work related accidents presenting on a weekend day was lower $(8 \%)$ compared to the proportion presenting on a weekday $(24 \%)$, irrespective of the total number of attendances on that particular day. Accidents as a result of domestic work only accounted for $4 \%$ of work related injuries during the study period. Table 1 shows the distribution of body parts injured.

Injuries to the hands and fingers were particularly common during the study period. We previously estimated 17 knife lacerations per 1000 employees per annum in some industrial sectors from these data (Harker et al., 1991). The high number of injuries to the lower limb include 38 ankle sprains resulting mainly from slips, trips or falls. A relatively small number of eye injuries are noted as the majority presented to the eye casualty unit during working hours.

The only investigations recorded on the casualty cards were radiographic examinations to exclude fractures or to locate radio-opaque foreign bodies. A total of 380 radiographs were taken at the time of initial presentation. Specific guidelines published since this study took place, have commented on the appropriate use of diagnostic radiographs in accident units (The Royal College of Radiologists, 1989). Review of the cases in this study did not suggest that any of these 380 examinations were inappropriate.

Table 1. The distribution of body parts injured of 578 patients attending the A\&E Department with work-related injuries.

\begin{tabular}{lcc}
\hline Body site & Number & Percentage \\
\hline Finger (s)/thumb/hand & 220 & 38.1 \\
Toe (s)/foot & 58 & 10.0 \\
Head and neck & 54 & 9.3 \\
Eye (s) & 31 & 5.4 \\
Back/chest/abdomen & 45 & 7.8 \\
Wrist/arm/shoulder & 63 & 10.9 \\
Ankle/leg/hip & 90 & 15.6 \\
Multiple location & 15 & 2.6 \\
Information insufficient & 2 & $<1$ \\
\hline
\end{tabular}


Table 2. Actions required to treat work-related injuries presenting to the A\&E Department.

\begin{tabular}{lcc}
\hline Action required & Number & Percentage \\
\hline Reassurance only & 16 & 1.8 \\
Surgical intervention & 30 & 3.3 \\
With local anaesthetic & & \\
Surgical intervention & 4 & $<1$ \\
With general anaesthetic & 3 & $<1$ \\
Observation in accident ward & 3 & $<1$ \\
Resuscitation & 168 & 18.5 \\
Tetanus toxoid and/or & & \\
Triplopen & 233 & 25.6 \\
Strapping/support bandage & 21 & 2.3 \\
Plaster of paris & 171 & 18.8 \\
Wound cleaned/dressing & 51 & 5.6 \\
Local anaesthetic and & & \\
Suturing of skin & 210 & 23.1 \\
Prescription (analgesics/antibiotics) & & \\
\hline
\end{tabular}

Table 2 lists action taken by the A\&E staff at the initial visit; treatment usually involved more than one of the actions listed.

Large numbers of support bandages, prophylactic injections and drug treatments were required to manage the occupational injuries. In addition to the action taken at the initial visit 165 out-patient appointments in the accident unit were required, 22 patients were admitted into hospital, and 19 patients were referred to other hospital-based specialists.

The attendances at the A\&E Department during the study period did not differ significantly from the average throughout the year. On this basis, we estimate that some $5100 \mathrm{X}$-ray examinations and 12300 medical treatments may be required for work-related accidents in this one hospital each year.

\section{DISCUSSION}

The information from this survey confirms that a significant amount of the A\&E Department's workload results from injuries sustained in the workplace. Many other injuries at work will be treated by smaller A\&E units in Grampian, general practioners, first-aiders, oil rig paramedics or occupational health units which provide a treatment service. An audit of our cases also confirms that the majority of referrals were appropriate and could not have been managed by first aiders or occupational health nurses based in the workplace. The training of occupational health nurses reflects this emphasis on accident and disease prevention rather than the provision of a treatment service. In addition the training of first aiders, particularly those who are safety representatives, could likewise encourage involve- 
ment in accident prevention programmes. In contrast, the unique nature of the offshore industry produces a requirement for paramedical treatment services in remote workplaces (Cox, 1982).

The need to administer tetanus toxoid to those victims of work-related accidents might be reduced by increased active immunization in the community to the levels suggested by the Department of Health and Social Security (DHSS, 1988). Employers of workers who are at risk of sustaining tetanus-prone wounds at work have a responsibility under the Control of Substances Hazardous to Health Regulations to ensure that measures such as immunization are undertaken to reduce the risk of infection (Health and Safety Commission, 1989). Against this can be put the probability that tetanus toxoid is administed too frequently in A\&E departments. In fact the level of immunization in the community might be quite high but patients are usually not aware of their personal status.

We estimate that, of the 228 injuries that occurred to the fingers, hands, toes and feet, $30 \%$ could have been prevented by wearing appropriate protective equipment (safety boots, chain mail gloves); other studies suggest that eye injuries could be substantially reduced by wearing safety glasses and goggles (Banerjee, 1990). In our experience many of the remaining injury types are also preventable by addressing working practices and the working environment, a procedure which involves all employees and managers alike.

Cooperation between professionals involved in treating industrial injuries and those with responsibility for safety in the workplace will lead to benefits for all concerned. It is hoped to introduce an accident prevention programme in specific industries in Grampian and to assess its success by continuing audits in the A\&E Department.

\section{REFERENCES}

Banerjee A. (1990) Effectiveness of eye protection in the metal working industry. British Medical Journal $30,645-646$.

Central Statistical Office. (1980) Standard Industrial Classification 1980. HMSO, London.

Cox R. A. F. (1982) Offshore Medical Care. In: R. A. F. Cox (Ed), Offshore Medicine, Medical Care of Eniployees in the Offshore Oil Industry. Springer-Verlag, New York.

Department of Health and Social Security. (1988) Immunisation against Infectious Disease. HMSO, London.

Grampian Health Board Information Services (1990).

Harker C., Matheson A. B., Ross J. A. S. \& Seaton A. (1991) Accidents in the Workplace. The Journal of the Society of Occupational Medicine 41, 73-76 (and erratum 41, 144).

Health and Safety Commission. (1986) Reporting of Injuries, Diseases and Dangerous Occurrences Regulations 1985 (RIDDOR) HMSO, London.

Health and Safety Commission. (1989) The Control of Substances Hazardous to Health Regulations 1988 (COSHH) HMSO, London.

Health and Safety Commission and Health and Safety Executive. (1990) Annual Report 1989/90. HMSO, London.

Health and Safety Executive. (1986) A Guide to the Reporting of Injuries Diseases and Dangerous Occurrences Regulations 1985 (RIDDOR). HMSO, London.

The Royal College of Radiologists. (1989) Making The Best Use of A Department Of Radiology - Guidelines For Doctors. The Royal College of Radiologists. London. ISBN 872599. 